\title{
Evaluation of tortuous vertebral arteries before cervical spine surgery: illustrative case
}

\author{
J. Manuel Sarmiento, MD, Justin D. Cohen, MD, Robin M. Babadjouni, MD, Miguel D. Quintero-Consuegra, MD, \\ Nestor R. Gonzalez, MD, and Tiffany G. Perry, MD
}

Department of Neurosurgery, Cedars-Sinai Medical Center, Los Angeles, California

BACKGROUND Cervical spine surgery sometimes necessitates complex ventral/dorsal approaches or osteotomies that place the vertebral artery (VA) at risk of inadvertent injury. Tortuosity of the VA poses increased risk of vessel injury during anterior decompression or placement of posterior instrumentation.

OBSERVATIONS In this report, the authors describe a patient with degenerative cervical spondylotic myelopathy and focal kyphotic deformity requiring corrective surgery via a combined ventral/dorsal approach. Computed tomography (CT) and CT angiography (CTA) of the spine identified a left medially enlarged C4 transverse foramen and tortuous VA V2 segment forming a potentially dangerous medial loop into the vertebral body, respectively. The patient's presentation and management are described.

LESSONS The course of the VA is variable, and a tortuous VA with significant medial or lateral displacement may be dangerous during ventral and dorsal approaches to the cervical spine. CTA of the cervical spine is warranted in cases in which atlantoaxial fixation is needed or suspicious transverse foramen morphology is identified to understand the course of the VA and identify anatomical variations that would put the VA at risk during cervical spine surgery.

https://thejns.org/doi/abs/10.3171/CASE2198

KEYWORDS tortuous; vertebral artery; cervical spine

Degenerative cervical spine disease may lead to cervical spinal stenosis and focal cervical kyphotic deformities. ${ }^{1}$ Surgical indications for correction of cervical kyphotic deformities and cervical stenosis include development of a neurological deficit, including myelopathy, severe mechanical pain, functional disability, or progression of deformity. ${ }^{2}$ The surgical management of degenerative cervical spinal stenosis with associated spinal instability may involve ventral decompression, dorsal instrumentation with or without decompression, and osteotomies for fixed flexion deformities-procedures that are all associated with potential vertebral artery (VA) injury.

The course of the VA is variable, ranging from an anomalous VA V1 segment entrance in the subaxial spine to a tortuous VA V2 segment within the transverse foramen and up to the upper cervical spine, where the VA V3 segment can be displaced from the sulcus arteriosus of the posterior arch of $\mathrm{C} 1 .^{3,4}$ Evaluation of the transverse foramen morphology on noncontrast computed tomography (CT) of the cervical spine can raise suspicion for anatomical VA variants. Normally, as the VA ascends cephalad, the transverse foramen moves from a more anterior and lateral position to a more posterior and medial position. ${ }^{5}$ Variations of the cervical vertebra transverse foramen have been associated with variations or asymmetry in the VA. ${ }^{6}$ Advanced preoperative imaging such as CT angiography (CTA) is recommended in such cases to understand the VA anatomy, identify anatomical VA variants, and prevent inadvertent VA injury. Patient presentations, management, and lessons learned are discussed.

\section{Illustrative Case}

A 67-year-old female with a past medical history of hypertension, type 2 diabetes mellitus, remote history of breast cancer in remission, and glutamic acid decarboxylase-positive $(G A D+)$ cerebellar degeneration presented with several months of neck pain with radiation and numbness into both arms for the past few months. She

ABBREVIATIONS $\mathrm{CT}=$ computed tomography; CTA $=$ computed tomography angiography; $\mathrm{GAD}+=$ glutamic acid decarboxylase-positive; MRI $=$ magnetic resonance imaging; $\mathrm{VA}=$ vertebral artery.

INCLUDE WHEN CITING Published May 17, 2021; DOI: 10.3171/CASE2198.

SUBMITTED February 17, 2021. ACCEPTED March 3, 2021.

(C) 2021 The authors, CC BY-NC-ND 4.0 (http://creativecommons.org/licenses/by-nc-nd/4.0/). 
also reported worsening gait instability despite stabilized GAD+ cerebellar degeneration while receiving intravenous immunoglobulin therapy, according to her neurologist. She had full strength in her upper and lower extremities, except for the strength in her left biceps and triceps, which were both $4+/ 5$. She was hyperreflexive bilaterally in her biceps, brachioradialis, patellar, and Achilles tendons. Hoffmann's sign was elicited bilaterally, but she had no evidence of clonus. She demonstrated a spastic gait on examination.

Cervical radiographs showed a flexible cervical kyphotic deformity with a sagittal Cobb angle of $6^{\circ}$ from $\mathrm{C} 4$ to $\mathrm{C} 6$. There was anterior subluxation of $\mathrm{C} 3$ on $\mathrm{C} 4, \mathrm{C} 4$ on $\mathrm{C} 5$, and $\mathrm{C} 5$ on $\mathrm{C} 6$ on dynamic flexion/extension radiographs (Fig. 1). Magnetic resonance imaging (MRI) of the cervical spine showed evidence of severe central canal stenosis at C3-4 and worse at C4-5 with associated spinal cord myelomalacia at both levels (Fig. 2). Preoperative CT identified a left VA traversing through the C4 vertebral body and uncinate process (Fig. 2). An enlarged right C2 transverse foramen, degenerated $\mathrm{C} 4$ lateral masses, and congenitally narrow C2 pedicles were also seen. A CTA scan was obtained to better define the VA anatomy and any anomalous vessels (Fig. 3). The CTA scan identified a left medially enlarged C4 transverse foramen and tortuous VA V2 segment, forming a potentially dangerous medial loop into the vertebral body up to the margin of the uncinate process. The distal VA V2 also medialized into the right C2 lateral mass (Fig. 4). The VAs entered the transverse foramina at the level of $\mathrm{C} 6$ on both sides.

A combined ventral/dorsal approach was proposed for ventral decompression and dorsal instrumentation with decompression. Thus, a C4-5 anterior cervical discectomy and fusion with structural allograft; posterior instrumentation from $\mathrm{C} 2$ to T1 using intraoperative $\mathrm{O}$-arm stereotactic navigation (Medtronic); and C3, C4, and C5 complete laminectomies were performed. Motor evoked potentials and somatosensory evoked potentials were monitored throughout the procedure. The ventral decompression at C4-5 was performed first, taking care to avoid the tortuous left VA that encroached into the C4 vertebral body by performing a careful discectomy and gentle decortication of the endplates of C4 and C5. A 5-mm structural allograft measuring $14 \times 11 \times 5 \mathrm{~mm}$ was successfully placed into the C4-5 intervertebral disc space, followed by a $17-\mathrm{mm}$ anterior plate secured into place by 4 screws. The left C4 screw was medialized more than usual to avoid the left VA coursing through that vertebral body. A 13-mm screw was used for the left side of the C4 vertebral body, and 15-mm screws were used for the right side of the C4 vertebral body as well as the bilateral C5 vertebral bodies. The patient was subsequently positioned prone, and a Mayfield skull clamp was used to secure the head and neck. Our initial plan for $\mathrm{C} 2$ fixation was to drill pilot holes using the $\mathrm{C} 1$ bit bilaterally for pedicle screws. However, since the right VA anatomy medialized into the right $\mathrm{C} 2$ lateral mass, we used a $3.5 \times 14-\mathrm{mm}$ pars screw with a trajectory aimed at the right $\mathrm{C} 2$ pedicle. A left-sided C2 $3.5 \times$ 20-mm pars screw with a trajectory aimed at the left $\mathrm{C} 2$ pedicle was successfully cannulated. Lateral mass pilot holes were then placed bilaterally at C3 and C5. The bilateral lateral masses at C4 were eroded and diminutive from degenerative changes, so we elected to avoid placing lateral mass screws at this level. Pedicle screw pilot holes were placed bilaterally at C7 and T1. A complete C3, C4, and C5 laminectomy was performed using a BoneScalpel (Misonix) to decompress the thecal sac. The facet joints at C2-3, C3-4, C5-6, C6-7, and C7-T1 were decorticated with a high-speed drill. Screws were placed bilaterally in their respective locations from $\mathrm{C} 2$ to $\mathrm{T} 1$, skipping the $\mathrm{C} 4$ and $\mathrm{C} 6$ levels. Postoperative radiographs showed good correction of the C4-5 subluxation and global correction of cervical kyphosis with an improved sagittal Cobb angle of $1^{\circ}$ from C4 to C6 (Fig. 5). The patient was discharged to a rehabilitation center on postoperative day 2 .

Of note, the patient sustained a fall 2 months later that led to a fractured right C2 pedicle, requiring revision surgery for removal of the right rod and $\mathrm{C} 2$ screw. This screw was replaced with a new right C2 translaminar screw. She was discharged to home the following day with home health assistance and a stable neurological examination.

\section{Discussion}

\section{Observations}

This illustrative case focuses on a 67-year-old female with a flexible cervical kyphotic deformity from degenerative disease, cervical spondylotic myelopathy, and cervical spinal cord compression causing neck pain, cervical radiculitis, and progressively worsening gait instability. Although this particular deformity was nonfixed and a posterior decompression with long segment fusion would put the VA at even less risk of injury, we elected to perform the operation using a combined ventral/dorsal approach. The ventral approach
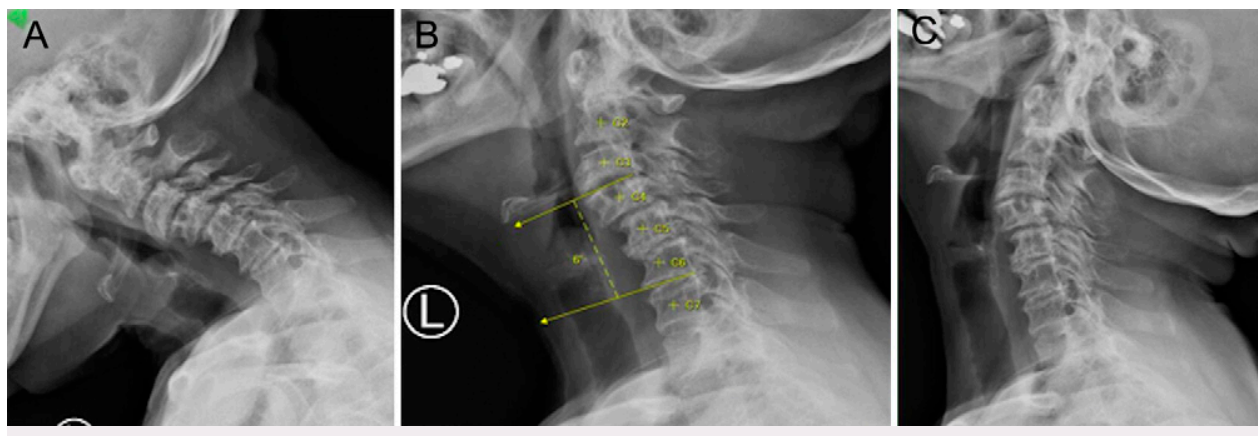

FIG. 1. Preoperative sagittal flexion (A), neutral (B), and extension (C) cervical radiographs showing a flexible cervical kyphotic deformity. Anterior subluxation of $\mathrm{C} 3$ on $\mathrm{C} 4, \mathrm{C} 4$ on $\mathrm{C} 5$, and $\mathrm{C} 5$ on $\mathrm{C} 6$ is seen. $\mathrm{A}$ Cobb angle of $6^{\circ}$ is measured from the superior endplate of $\mathrm{C} 4$ to the inferior endplate of $\mathrm{C} 6$ (B). 


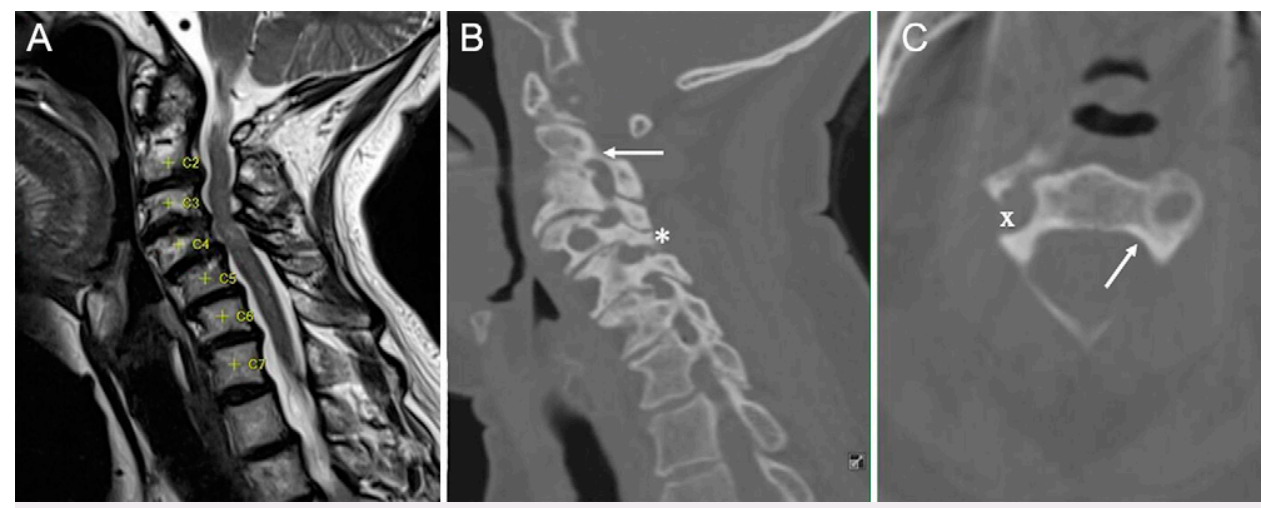

FIG. 2. Sagittal MRI (A) of the cervical spine showing evidence of severe central canal stenosis at C3-4 and worse at C4-5 with associated spinal cord myelomalacia. Sagittal CT (B) of the cervical spine showing an enlarged C4 transverse foramen at the center of the vertebral body. An eroded and diminutive left C4 lateral mass is seen (asterisk). The left C2 pedicle is narrow (arrow). Axial CT (C) of the cervical spine showing an enlarged right $\mathrm{C} 2$ transverse foramen $(X)$ and congenitally narrow pedicle (arrow).

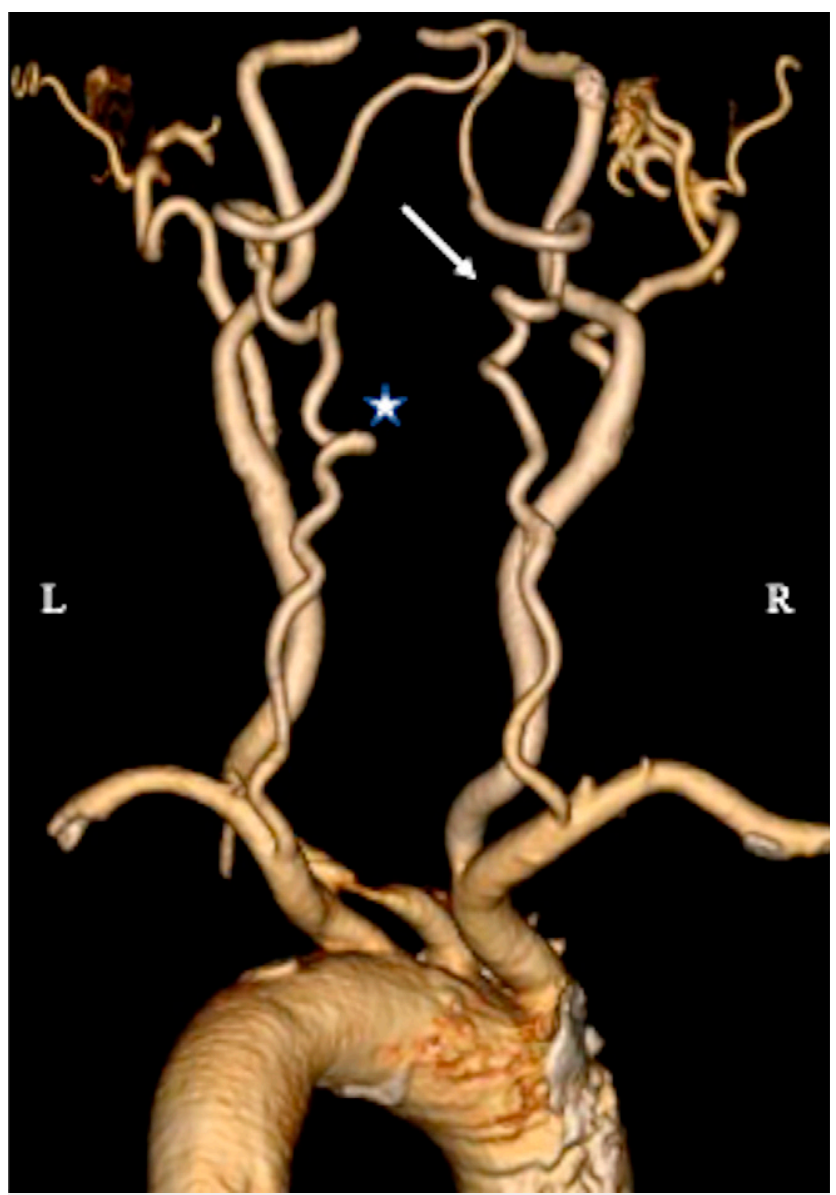

FIG. 3. Three-dimensional CTA showing a medial loop in the left VA mid-V2 segment at C4 (star) and a medial loop in the right VA distalV2 segment at C2 (arrow). permitted decompression of the C4-5 intervertebral disc as well as anterior column reconstruction with a structural allograft and instrumentation to help attain a more lordotic cervical posture. Therefore, we thought this approach helped achieve a better correction of the focal deformity and anterior subluxation at the C4-5 level. Multiple laminectomies were needed to decompress the spinal cord from stenosis caused by ligamentum flavum buckling. Finally, the dorsal construct provided a long moment arm to aid in the prevention of further deformity progression. Fortunately, this patient's tortuous left C4 vertebral body and right C2 transverse foramen VA anomalies were evaluated during preoperative planning, so intraoperative adjustments could be made to prevent VA laceration. These VA anomalies were first seen and suspected in the preoperative cervical MRI and were later confirmed with CT and CTA of the cervical spine.

The VA has a complex and variable course, beginning at the origin from the subclavian artery and terminating intracranially to form the basilar artery. The VA is classically divided into the following 4 segments: V1 starts from its origin on the subclavian artery to the $\mathrm{C} 6$ transverse process, V2 from $\mathrm{C} 6$ to the $\mathrm{C} 2$ transverse process, V3 from $\mathrm{C} 2$ to the foramen magnum, and $\mathrm{V} 4$ from the foramen magnum dura to the vertebrobasilar junction. ${ }^{7}$ In their cadaveric studies, Hong et al. ${ }^{8}$ reported VA entrance into the C6 transverse process in $94.9 \%$ of cadaveric specimens (664 of 700 VA courses). An abnormal VA entrance was observed in $5.1 \%$ of specimens (36 VA courses), with entrance into the $\mathrm{C} 4, \mathrm{C} 5$, or $\mathrm{C} 7$ transverse foramen in $1.6 \%, 3.3 \%$, and $0.3 \%$ of cases, respectively. ${ }^{8}$ These findings correlate with the radiographic findings of Bruneau et al., ${ }^{3}$ who evaluated 500 VAs on $200 \mathrm{MRI}$ scans and 50 contrast-enhanced CT scans. In their study, the VA entered the C6 transverse foramen in $93 \%$ of all specimens. VA entrance into the $\mathrm{C} 4, \mathrm{C} 5$, and $\mathrm{C} 7$ transverse foramen was observed in $1 \%, 5 \%$, and $0.8 \%$ of cases, respectively. ${ }^{3}$ This is clinically significant because based on the values reported in this study, the abnormal level of VA entrances was higher than the C6 level in $6.2 \%$ of cases. In these cases, the VA V1 segment would run unprotected by a transverse process at the level of $\mathrm{C} 6$ and would be beneath the longus colli muscle, where it would be at risk for injury. 

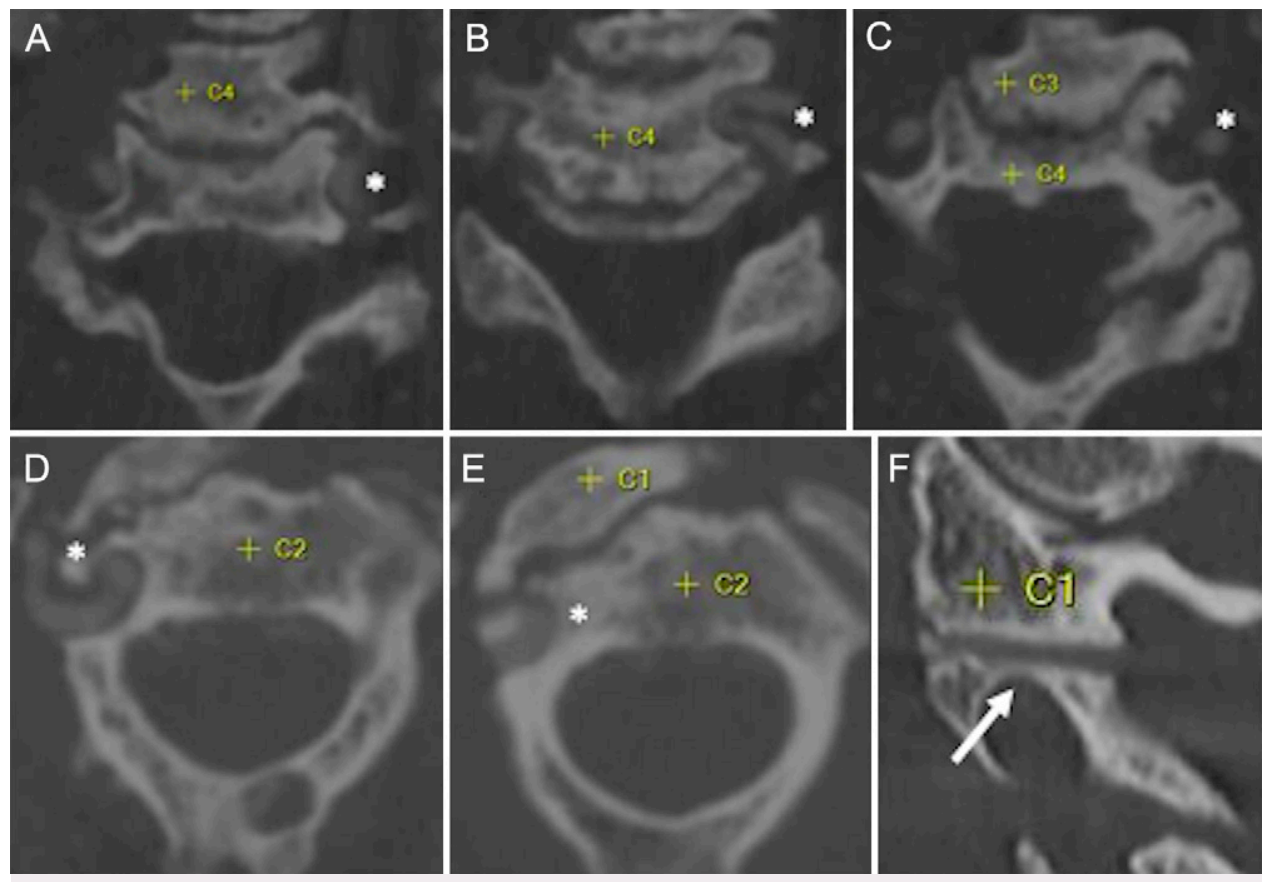

FIG. 4. Axial CTA scans at the level of lower C4 vertebra (A), midlevel C4 vertebra (B), and upper C4 vertebra (C) showing a left medially enlarged C4 transverse foramen and tortuous VA V2 segment (asterisks) forming a medial loop into the $\mathrm{C} 4$ vertebral body up to the margin of the uncinate process. Axial CTA scans of the midlevel C2 vertebra (D) and upper C2 vertebra (E) showing a right tortuous VA distal-V2 segment (asterisks) medialized into the lateral mass. Sagittal CT scan showing an enlarged right C2 transverse foramen and narrow isthmus (F; arrow).

The morphology of the transverse foramina in the cervical spine may be an indication of an underlying VA anomaly. According to Zibis et al., ${ }^{6}$ variations of the foramen transversarium can be found in up to $30 \%$ of patients. Furthermore, $60 \%$ of patients exhibiting variations in the transverse foramen were also exhibiting variations or asymmetry in the VA, compared with $25.7 \%$ of patients with no foramen variations $(p=0.02){ }^{6}$ Various other studies have confirmed the presence of anomalous VA routes in the V2 segment. In 2 (5.6\%) of 36 abnormal VA entrances, the extraosseous VA formed an unusual medial loop, according to Hong et al. ${ }^{8}$ Bruneau et al. reported that $5(2 \%)$ of 250 patients demonstrated an unusual medial loop of the VA V2 segment into an unusually large transverse foramen. ${ }^{3}$ Curylo et al. ${ }^{9}$ reported a $2.7 \%$ incidence of a tortuous, medially located VA in 7 of 222 cadaveric spines. The abnormalities were present at $\mathrm{C} 3$ in 3 specimens, $\mathrm{C} 4$ in 3 specimens, and $\mathrm{C} 6$ in 1 specimen. All anomalies were unilateral. Five of the anomalies were located in the left side, and 2 were in the right side. ${ }^{9}$ This study also highlights an important example of a case in which the medial VA was not identified in preoperative planning and was subsequently lacerated at the midbody of $\mathrm{C} 4$ during a 3-level anteriorcervical corpectomy. The bleeding was controlled by temporarily clamping the VA in front of $\mathrm{C}$. The laceration was repaired directly by a vascular surgeon.

Important anatomical variations of the VA in the upper cervical spine may exist among individuals. In fact, a limiting factor of $\mathrm{C} 1-2$ internal fixation is the location of the VA. The 3 types of VA variants in the craniocervical junction are a persistent first intersegmental artery, extracranial C1-2 origin of the posterior inferior cerebellar artery, and fenestration of the VA. ${ }^{4}$ CTA is recommended to identify the actual location of the VA in cases in which a cervical spine deformity requires atlantoaxial fixation. Moftakhar et al. showed radiographically that there is significant variation in the location of the VA within the VA groove of the atlas. ${ }^{10}$ Abtahi et al. ${ }^{11}$ described a case in which a left-sided persistent first intersegmental artery was identified preoperatively in a patient requiring $\mathrm{C} 1-2$ fixation. To avoid risking VA injury during $\mathrm{C} 1$ lateral mass screw placement, they elected to perform an occiput-to-C3 posterior spinal fusion instead. ${ }^{11}$ Another VA anomaly in the upper cervical spine is ponticulus posticus-a bony prominence arising from the posterior arch or superior articulating process of $\mathrm{C} 1$ that completely or partially encircles the VA. ${ }^{12}$ Jung et al. recently published an operative video describing a 79-year-old patient with right-sided ponticulus posticus who was treated with $\mathrm{C} 1$ laminectomy, microdissection of the VAs, and placement of $\mathrm{C} 1$ pedicle screws. ${ }^{13}$ This example highlights the significant variability of the vascular anatomy in the upper cervical spine and demonstrates how screw trajectories should be designed on an individual basis.

Injury to the VA during cervical spine surgery can have disastrous consequences, such as pseudoaneurysm formation and posterior circulation stroke. The rate of VA injury ranges from $0.07 \%$ to $0.14 \%$, and injury may occur in both anterior and posterior approaches to the cervical spine. ${ }^{14}$ Although VA injuries are uncommon, they may cause permanent neurological impairment or death in as high a proportion as $10 \%$ of injured patients. ${ }^{15} \mathrm{~A} 2017$ systematic review by Guan et al..$^{16}$ reported iatrogenic VA injury during anterior cervical surgery. Common 


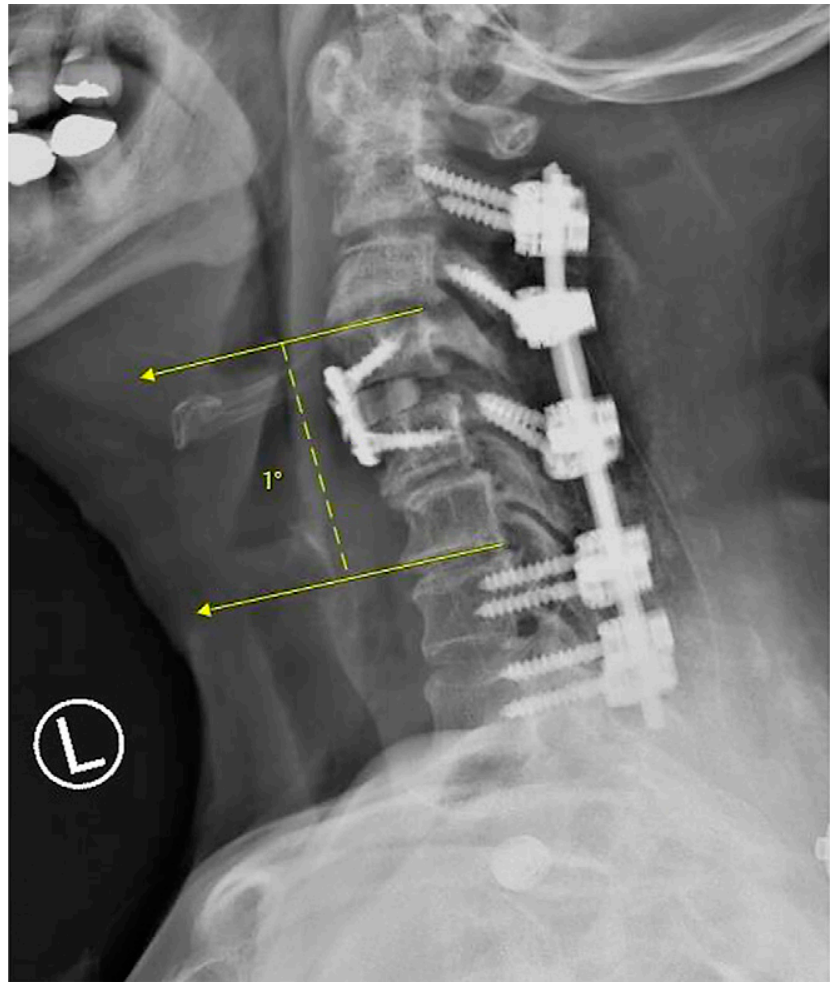

FIG. 5. Postoperative sagittal cervical radiograph showing good correction of the C4-5 subluxation and segmental correction of cervical kyphosis. Cobb angle of $1^{\circ}$ is measured from the superior endplate of $\mathrm{C} 4$ to the inferior endplate of $\mathrm{C} 6$.

presentations of VA injury included copious surgical bleeding, delayed hemorrhage of pseudoaneurysm with neck swelling, dyspnea, hypotension, and cervical bruits caused by arteriovenous fistulas. Lack of preoperative knowledge of the VA course had increased the occlusion risk and neurological sequelae. ${ }^{16}$ If VA injury occurs, digital pressure followed by large pieces of thrombin gel foam, avitene, or other non-embolic agents may be used to achieve hemostasis. Definitive treatment may then be achieved by primary repair with 7-0 or 8-0 Prolene suture after temporary aneurysm clips are placed proximally and distally to the injury site. If primary repair is not feasible, bypass surgery, endovascular stenting, or vessel sacrifice may be considered. Belykh et al. published an elegant illustrative study with operative photographs of stepwise techniques to successfully repair an inadvertent VA injury during a C3-6 discectomy and fusion procedure. ${ }^{17}$

\section{Lessons}

The course of the VA is variable, and a tortuous VA with significant medial or lateral displacement may be dangerous during ventral and dorsal approaches to the cervical spine. CTA of the cervical spine is warranted in cases in which atlantoaxial fixation is needed or suspicious transverse foramen morphology is identified on a CT scan. This allows the surgeon to understand the course of the VA and identify anatomical variations that would put the VA at risk during cervical spine surgery.

\section{References}

1. Johnston FG, Crockard HA. One-stage internal fixation and anterior fusion in complex cervical spinal disorders. J Neurosurg. 1995;82(2):234-238.

2. Steinmetz MP, Stewart TJ, Kager CD, et al. Cervical deformity correction. Neurosurgery. 2007;60(1 suppl):S90-S97.

3. Bruneau M, Cornelius JF, Marneffe V, et al. Anatomical variations of the V2 segment of the vertebral artery. Neurosurgery. 2006; 59(1 suppl):ONS20-ONS24.

4. Uchino A, Saito N, Watadani T, et al. Vertebral artery variations at the $\mathrm{C} 1-2$ level diagnosed by magnetic resonance angiography. Neuroradiology. 2012;54(1):19-23.

5. Vaccaro AR, Ring D, Scuderi G, Garfin SR. Vertebral artery location in relation to the vertebral body as determined by two-dimensional computed tomography evaluation. Spine (Phila Pa 1976). 1994;19(23):2637-2641.

6. Zibis A, Mitrousias V, Galanakis N, et al. Variations of transverse foramina in cervical vertebrae: what happens to the vertebral artery? Eur Spine J. 2018;27(6):1278-1285.

7. Heary RF, Albert TJ, Ludwig SC, et al. Surgical anatomy of the vertebral arteries. Spine (Phila Pa 1976). 1996;21(18):2074-2080.

8. Hong JT, Park DK, Lee MJ, et al. Anatomical variations of the vertebral artery segment in the lower cervical spine: analysis by threedimensional computed tomography angiography. Spine (Phila $\mathrm{Pa}$ 1976). 2008;33(22):2422-2426.

9. Curylo LJ, Mason HC, Bohlman HH, Yoo JU. Tortuous course of the vertebral artery and anterior cervical decompression: a cadaveric and clinical case study. Spine (Phila Pa 1976). 2000;25(22):2860-2864.

10. Moftakhar P, Gonzalez NR, Khoo LT, Holly LT. Osseous and vascular anatomical variations within the $\mathrm{C} 1-\mathrm{C} 2$ complex: a radiographical study using computed tomography angiography. Int J Med Robot. 2008;4(2):158-164.

11. Abtahi AM, Brodke DS, Lawrence BD. Vertebral artery anomalies at the craniovertebral junction: a case report and review of the literature. Evid Based Spine Care J. 2014;5(2):121-125.

12. Huang DG, Hao DJ, Fang XY, et al. Ponticulus posticus. Spine J. 2015;15(11):e17-e19.

13. Jung YG, Lee BJ, Park W, Park JH. C1-2 pedicle screw fixation for ponticulus posticus and duplication of vertebral artery: 2-dimensional operative video. Oper Neurosurg (Hagerstown). 2021;20(4):opaa397.

14. Neo M, Fujibayashi S, Miyata M, et al. Vertebral artery injury during cervical spine surgery: a survey of more than 5600 operations. Spine (Phila Pa 1976). 2008;33(7):779-785.

15. Lunardini DJ, Eskander MS, Even JL, et al. Vertebral artery injuries in cervical spine surgery. Spine J. 2014;14(8):1520-1525.

16. Guan $Q$, Chen L, Long $Y$, Xiang Z. latrogenic vertebral artery injury during anterior cervical spine surgery: a systematic review. World Neurosurg. 2017;106:715-722.

17. Belykh E, Xu DS, Yağmurlu K, et al. Repair of V2 vertebral artery injuries sustained during anterior cervical diskectomy. World Neurosurg. 2017;105:796-804.

\section{Disclosures}

The authors report no conflict of interest concerning the materials or methods used in this study or the findings specified in this paper.

\section{Author Contributions}

Conception and design: Gonzalez, Sarmiento, Perry. Acquisition of data: Sarmiento, Babadjouni, Perry. Analysis and interpretation of data: Gonzalez, Sarmiento, Babadjouni, Perry. Drafting the article: Sarmiento, Cohen, Babadjouni, Quintero-Consuegra, Perry. Critically revising the article: Sarmiento, Babadjouni, Quintero-Consuegra, Perry. Reviewed submitted version of manuscript: Gonzalez, Sarmiento, Perry. Approved the final version of the manuscript on behalf of all authors: Gonzalez. Statistical analysis: Babadjouni. Administrative/technical/material support: Perry. Study supervision: Sarmiento. 


\section{Supplemental Information}

Online-Only Content

Supplemental material is available with the online version of the article. Supplemental Illustrative Cases. http://thejns.org/doi/suppl/10.3171/ CASE2198.

\section{Correspondence}

Nestor R. Gonzalez: Cedars-Sinai Medical Center, Los Angeles, CA. nestor.gonzalez@cshs.org. 